\title{
Is there any association between obstructive sleep apnea (OSA) and aspirin-exacerbated respiratory disease (AERD)? Does aspirin desensitization affect OSA risk?
}

\author{
Fatma Merve Tepetam ${ }^{1 *}$, Gülgün Çetintaş Afşar ${ }^{2}$ and Sema Saraç² \\ ${ }^{1}$ University of Health Sciences Sureyyapasa Chest Diseases and Thoracic Surgery Training and Research Hospital Department of Immunology and Allergy, İstanbul, Turkey \\ ${ }^{2}$ University of Health Sciences Sureyyapasa Chest Diseases and Thoracic Surgery Training and Research Hospital Department of Chest Diseases, İstanbul, Turkey
}

\begin{abstract}
Objective: Aspirin-exacerbated respiratory disease (AERD) is characterized by asthma, eosinophilic rhinosinusitis, recurrent nasal polyposis, and hypersensitivity reactions to aspirin or any other nonsteroidal antiinflammatory drugs (NSAİDs). In our study, we thought that, in adult patients with AERD, obstructive sleep apnea (OSA) may develop more frequently due to both lower and upper respiratory tract inflammation associated with cysLTs; and so we compared OSA frequency and severity in patients with AERD, asthma with rhinosinusitis without hypersensitivity reaction to aspirin or NSAIDs ( Aspirin tolerant respiratory disease; ATRD) and in patients without asthma and rhinitis (Control group).
\end{abstract}

Materials and methods: In the retrospective case control study patients who are followed in our immunology and allergy clinic and to whom performed polysomnography because of any OSA releated symptoms were collected for AERD group. ATRD and control group were selected from polysomnography records. 15 patients with AERD group, 11 with ATRD group and 11 with control group were matched with age, sex, and body mass index (BMI).

Results: In this study we have observed that AERD and ATRD groups have frequently OSA (40\%, 72.2\% respectively), but control group 18.18\% have. Although mean FEV1 is lower in AERD group, reversly AHI is higher in ATRD group. In the group of AERD with aspirin desensitizated, OSA was seen in 22.22\%; but in nondesensitizated goup OSA was seen in $66.66 \%$ patients $(\mathrm{p}=0.085)$. In the AERD group number of polypectomy operation and AHI were significantly correlated $(\mathrm{p}=0.001, \mathrm{r}=0.74)$.

Conclusion: To our best knowledge this is the first study demonstrated that AERD and OSA have been associated with each other; it seems to be affected by aspirin desesitization and number of nasal polypectomy operation.

\section{Introduction}

Samter's Triad also called Aspirin-exacerbated respiratory disease (AERD) is characterized by asthma, eosinophilic rhinosinusitis, recurrent nasal polyposis, and hypersensitivity reactions to aspirin or any other nonsteroidal antiinflammatory drugs (NSAIDs) which inhibit the cyclooxygenase 1 (COX-1) enzyme [1]. After blocking COX1 enzyme arachidonic acid is oxidized by 5-lipoxygenase (LO) and marker of systemic cysLTs ( LTC4, LTD4 and LTE4 levels) production are increased [2]. The cysLTs induce bronchoconstriction, activation of eosinophils and so remodelings in both upper and lower airways [3].

Obstructive sleep apnea (OSA) is characterized by pharyngeal constriction during sleep, which causes sleep disruption, snoring, choking, frequent awakenings, and excessive daytime. OSA has been shown to be associated with inflammation of both the upper and lower airways too [4]. While a number of pathophysiological mechanisms may contribute to OSA formation, CysLTs play a major role with not only local effects but also with systemic relations especially in children with adenotonsillar hypertrophy [5-8]. Besides adenotonsillar hypertrophy, many nose and pharynx abnormalities such as septal deviation, nasal polyps, turbinate hypertrophy, and rhinitis may cause OSA [9-11]. Most possible etiology for the high prevalence of OSA symptoms in asthmatic patients is increasing incidence of nasal obstruction and upper airway collapsibility reason of accompanied rhinitis to asthma frequently [12-14].

To the extent that although all the components of the AERD have been shown to be related to the OSA, relationship of OSA with cysLTs that play a role in the pathogenesis of AERD were investigated only in children with adenoid hypertrophy. In our study, we thought that, in adult patients with AERD, OSA may develop more frequently due to both lower and upper respiratory tract inflammation associated with cysLTs; and so we compared OSA frequency and severity in patients with AERD, asthma with rhinosinusitis without hypersensitivity reaction to aspirin or NSAIDs (Aspirin tolerant respiratory disease; ATRD) and in patients without asthma and rhinitis (Control group).

Correspondence to: Fatma Merve Tepetam, University of Health Sciences Süreyyapaşa Chest Diseases and Thoracic Surgery Training and Research Hospital Departmant of Immunology and Allergy Başıüyük mah, Maltepe Istanbul, Turkey, Tel: + 90 5065048746; Fax:+ 90216 4214150; E-mail: fatmamervealan@hotmail.com

Key words: Aspirin-exacerbated respiratory disease (AERD), Aspirin tolerant respiratory disease (ATRD), Obstructive sleep apnea (OSA)

Received: October 17, 2017; Accepted: November 01, 2017; Published: November 04, 2017 


\section{Materials and methods}

\section{Study design}

22 patients with AERD have been followed in our immunology and allergy clinic between 2013 and 2017. From this group 15 patients to whom performed polysomnography because of any OSA releated symptoms (daytime sleepiness, sleep disruption, snoring, choking and apnea) were included in the study for AERD group. ATRD and control group were selected from polysomnography records between 2013 and 2017 with symptoms of snoring; while ATRD group have upper and lower respiratory diseases, control group have not any comorbidites including asthma and/or rhinosinusitis. We have taken into account that selected control group have similar symptoms of apne, daytime sleepiness and Epworth sleepiness scale (ESS) compared with the group of AERD. Subjects with smoking history more than 5 packet/ years, continue smoking, chronic obstructive pulmonary diseases (COPD), chronic renal diseases, chronic liver diseases, cardiovascular diseases, cerebrovascular diseases, and other sleep-related disorders like sleep-related hypoxemia/hypoventilation syndrome (SRHHS) were excluded. 15 patients with AERD group, 11 with ATRD group and 11 with control group were matched with age, sex, and body mass index (BMI) in the study.

The retrospective case control study protocol was approved by the Ethics Committee of University of Health Sciences Sureyyapasa Chest Diseases and Thoracic Surgery Training and Research Hospital.

\section{Clinical assesment}

AERD patients was defined when asthma is diagnosed according to GINA and had a history of asthma or rhinitis attacks related to acetylsalicylic acid (ASA) or other NSAIDs and had nasal polyposis or had been operated on for it. ATRD patients defined when moderate or severe asthma was signed according to GINA at least 3 th step treatment (combined with inhaler steroid and bronchodilator) with rhinosinusitis history without any reactions after ingestion of ASA or NSAIDs [15]. Control group defined wihout asthma, rhinosinusitis and drug reaction history.

In our immunology and allergy department for group AERD; history of atopic disease and drug adverse reaction history was filled out, physical examination, pulmonary function tests, skin-prick tests with common aeroallergens (ALK-Abello, Madrid, Spain) were performed and blood analysis was made; total IgE and eosinophil count were assesed for each patient.

\section{Oral aspirin provocation and desensitization}

We applied the protocol to the patients with AERD who accepted and whose forced expiratory volume in 1 second (FEV1) was more than $1.5 \mathrm{~L}$ and $60 \%$ of predicted. On the 1 st day placebo, 2 nd day at the begining dose of $20 \mathrm{mg}$ of aspirin were given 90 minute intervals at increasing doses. During the procedure, blood pressure and FEV1 values, as well as the skin, ocular, nasal, and bronchial reactions, were monitored; If any reaction was occured patients were treated according to the reaction type. Aspirin desensitization was completed at the last dose of $600 \mathrm{mg}$ aspirin and than patients treated with $300 \mathrm{mg}$ twice daily [16]. Of the 15 AERD patients, 10 consented to undergo aspirin desensitization. 9 of these patients were successfully desensitizated, with one desensitization failure due to severe gastrointestinal symptoms during the desensitization procedure. 2 patient's aspirin treatment were discontinued, because of 1 patient have developed minimal gastrointestinal bledding and emergence of Familial Mediterranean fever (FMF) after 6 mounth of treatment, other patient has stopped the treatment before herni operation, than not begun because more than 72-96 hour interrupting the treatment, aspirin desnsitization protocol must be repeated. This stuations were observed after polysomnography was performed

\section{Polysomnography}

Nocturnal polysomnography was performed with multichannel monitoring (Grass-Telefactor Cephalo, An Astro-med Inc. Product Group, 2005, USA) that includes neurophysiological electrodes (electroencephalography electrodes), electrocardiography electrodes chest wall motion, abdominal motion and arterial oxygen saturation. For measuring oronasal airflow thermistor, for body position, sensor attached to the anterior chest wall and for monitoring oxyhemoglobin saturation finger pulse oximeter with a sampling rate of $1 \mathrm{~Hz}$ was used. Signals recorded in the sleep period were manually analyzed. If airflow decreased by at least $90 \%$ from the baseline for at least $10 \mathrm{~s}$ classified as apnea and according to the occurrence of thoracoabdominal movements central, mixed, or obstructive apnea were specified [17]. If airflow decreased by at least $30 \%$ for $\geq 10 \mathrm{~s}$ and were associated with a oxygen saturation $\left(\mathrm{SO}_{2}\right)$ fall $\geq 3 \%$ were scored as hypopneas. Oxygen desaturation index (ODI) is the hourly average number of desaturation episodes, which are defined as at least $4 \%$ decrease in saturation from the average saturation in the preceding 120 seconds, and lasting 10 seconds. $\mathrm{SO}_{2}$ in the sleep period was automatically analyzed, and after manual elimination of possible artifacts, mean $\mathrm{SO}_{2}$ and minimum nocturnal $\mathrm{SO}_{2}$ values were detected. Subjects with $\mathrm{AHI} \geq 5 / \mathrm{h}$ were considered to have OSA while subjects with $\mathrm{AHI}<5 / \mathrm{h}$ were considered as heathy controls [18].

\section{Statistical analysis}

If normally distribution was observed results were expressed as mean \pm standard deviation (SD), if not median and (25-75 percentile) were expressed. Significance of difference between AERD, ATRD and control group in terms of age, BMI and ESS were investigated with ANOVA test, for AHI and ODI Kruskal- Wallis test and for categorical parameters Chi-square test was used. The relation between AHI and number of polypectomy; AHI and eosinophil level were investigated with pearson correlation test. The statistical analysis were performed using the SPSS program (SPSS Inc., IL, USA) and $\mathrm{p}$ values were analysed using two tailed; statistically significant was considered if $p$ values were less than 0.05 .

\section{Results}

The groups of AERD, ATRD and control were included 15, 11 and 11 patients respectively. Table 1 showed the baseline characteristics of the groups. There was no significant difference between the three groups in terms of mean age, sex and BMİ. Mean FEV1 was significantly lower in AERD group than ATRD group; but more of the control groups file did not contain spirometric test results so assigned as not recorded (NR).

When we compared the groups as symptoms of snoring, apnea and ESS; snoring were seen in all of the patients, As we described in methods we have matched the presence of apnea, daytime sleepiness symptom and ESS score in the group of AERD and control. But in ATRD group mean ESS score was significantly higher and presence of apnea symptom were higher too, but there was no statistical significance. $(p=0.008$ and $\mathrm{p}=0.05$ respectively). Median AHI was significantly higher in ATRD group ( $\mathrm{p}=0.027$ ). But there was no difference in terms of ODI between groups $(\mathrm{p}=0.190)$. As seen in table 2 , OSA was significantly more observed in ATRD group ( $\mathrm{p}=0.029)$. 

affect OSA risk?

Table 1. Baseline characteristics of the groups.

\begin{tabular}{|c|c|c|c|c|}
\hline & AERD ( n=15) & ATRD (n=11) & Control (n=11) & p value \\
\hline $\begin{array}{c}\text { Age: mean } \\
( \pm \text { SD) }\end{array}$ & $43.20(13.99)$ & $43.36(4.78)$ & $43.22(10.97)$ & 0.998 \\
\hline Sex:women/men & $9 / 6$ & $4 / 7$ & $7 / 4$ & 0.367 \\
\hline $\begin{array}{c}\text { BMI: mean } \\
( \pm \text { SD) }\end{array}$ & $26.19(4.99)$ & $29.90(4.07)$ & $26.66(4.36)$ & 0.113 \\
\hline ESS $( \pm$ SD) & $5.71(4.17)$ & $11.30(5.63)$ & $6.27(2.68)$ & $0.008^{\mathrm{a}}$ \\
\hline $\begin{array}{c}\text { FEV1: mean } \\
( \pm \text { SD) }\end{array}$ & $80.43(14.47)$ & $99.80(14.20)$ & NR & $0.004^{\mathrm{b}}$ \\
\hline
\end{tabular}

Abbreviations: AERD: Aspirin-exacerbated respiratory disease, ATRD: Aspirin tolerant respiratory disease, BMI: Body mass index, ESS: Epworth sleepiness scale, FEV1: Forced expiratory volume in 1 second. NR: Not recorded.

Notes: ${ }^{\mathrm{a}}$ ANOVA test, ${ }^{\mathrm{b}}$ independent sample t-test

Table 2. Comparison of polysomnographic data between the groups.

\begin{tabular}{|c|c|c|c|c|}
\hline & AERD (n=15) & ATRD (n=11) & Control (n=11) & p value \\
\hline $\begin{array}{c}\text { AHİ; median } \\
\text { (percentile 25-75) }\end{array}$ & $\begin{array}{c}1.89 \\
(0.30-10.30)\end{array}$ & $\begin{array}{c}9.21 \\
(4.61-27.30)\end{array}$ & $\begin{array}{c}1.50 \\
(0.70-4.80)\end{array}$ & $0.027^{\mathrm{a}}$ \\
\hline $\begin{array}{c}\text { ODİ; median } \\
\text { (percentile 25-75) }\end{array}$ & $\begin{array}{c}2 \\
(1-12)\end{array}$ & $\begin{array}{c}8.72 \\
(5-26)\end{array}$ & $\begin{array}{c}3.40 \\
(0.90-7.50)\end{array}$ & 0.190 \\
\hline OSA; n (\%) & $6(40)$ & $8(72.72)$ & $2(18.18)$ & $0.034^{\mathrm{b}}$ \\
\hline
\end{tabular}

Abbreviations: AERD: Aspirin-exacerbated respiratory disease, ATRD: Aspirin tolerant respiratory disease, AHI: Apnea hipopnea index, ODI: Oxygen desaturation index, OSA: Obstructive sleep apnea

Notes: ${ }^{\mathrm{a}}$ Kruskal- Wallis test, ${ }^{\mathrm{b}} \chi 2$ test

8 of the 15 AERD patients had positive skin prick test results and most detected allergens of the patients were house dust mite. Mean eosinophil, total IgE levels and other characteristic features of the patients with and without aspirin desesitizated were seen in table 3. Aspirin desensitization was succesfully performed to 9 patient. While 2 patient had OSA from the 9 desensitizated supgroup (22.22\%), 4 patient had OSA from the 6 nondesensitizated subgroup $66.66 \%, \mathrm{p}=0.086$ ). There was no corelation between duration of aspirin treatment (time interval between desensitization date and polysomnography performed date) and AHI, but there was significant corelation between number of nasal polip operation and AHI (Figure $1 \mathrm{p}=0.001, \mathrm{r}=0.74$.).

\section{Discussion}

In this study we have observed that AERD and ATRD groups have frequently OSA ( $40 \%, 72.2 \%$ respectively). Although mean FEV1 is lower in AERD group, reversly AHI is higher in ATRD group. This stuation may be realeted the ATRD group have high ESS score and OSA symptoms. In the group of AERD with aspirin desensitizated, OSA was seen in $22.22 \%$; while in nondesensitizated goup OSA was seen in \% 66.66 patients $(\mathrm{p}=0.085)$. In the AERD group number of polypectomy operation and AHI were significantly correlated.

The prevalence of OSA was higher in our study population, but to our best knowledge there was no study investigated OSA prevalence in AERD. Several studies have proposed a link between OSA and the diseases of rhinitis or asthma which are the components of ATRD and AERD. A Turkish study showed that while $36 \%$ of patients with a. rhinitis have OSA, $82 \%$ of non allergic rhinitis have OSA [19]. On the other hand epidemiologic data showed that asthmatic populations have OSA ranges from 38-70\% [20]. In a recent prospective study for screening OSA in asthma patients, $63.41 \%$ of the subjects have OSA but in asthma accompanied by a rhinitis $85 \%$ have OSA; In this study they specified that $49.59 \%$ were mild, $43.9 \%$ were moderate $6.5 \%$ were severe asthma and mean FEV1 was $87.63 \%$ [21]. In our study according to drug history $72.72 \%$ of the ATRD group were taking low dose inhaler steroid combined with longacting beta2 agonist (3'th step to GINA; moderate) others were taking 4'th step (severe), but our all of the AERD patient's treatment were at least 4'th step and 2 of them taking also omalizumab treatment. As seen in AERD group asthmatic patients were more severe and have lower FEV1 (80.14\%) contrastly OSA prevalence was lower than ATRD group. This may be because of ATRD group's prick test results were not recorded, if nonallergic patients more frequently, as described above, risk of OSA may be increased but most of the AERD patients prick tests were positive $(52.33 \%)$ and other reason of lower risk of OSA is, AERD is included in late onset phenotip of asthma. Also we are avare of AERD patients have risk of OSA and all of the patients with snoring redirected to our sleep policlinic. But ATRD group were selected from polysomgrapy records and as seen they were more symptomatic (selection bias). On the other hand control group have smilar symptoms compared with AERD group but OSA was seen in lower rates in control subjects (18.18\%). Our other limitations were neck circumference, gastroesophageal reflux disease (GERD) and dyslipidemia were not recorded and may effect the results.

Although there was no study about AERD and OSA association, cysLTs which were playing a role in AERD development, have been demostrated that may contribute to OSA formation. Besides cysLTs, eosinophil cationic protein increased significantly in AERD [5-8]. But in OSA with asthmatic patients, it has been shown that rather than eosinophils, neutrophils were higher proportion in induced sputum and they were correlated with AHİ [22,23]. Contraversely in our study high blood eosinophil levels were detected in AERD group and not correlated with AHİ. We can explain this, AERD which is eosinophilic phenotip of asthma, have lower risk of OSA than severe neutrophilic phenotip of asthma. Nasal polyp is other component of AERD, and associated with OSA; in a report two cases have high AHI after surgery despite sypmtoms were relieved [24]. We desesitizate patients after nasal polypectomy if required, so all of the patients polysomnagraphy was performed after surgery. OSA was seen lower in desensitizated group than nondesensitizated; may be result from decreased airway inflammation. Polypectomy was significantly correlated with AHI thought the reason of nasal reseptors alteration after sugery.

\section{Conclusion}

This is the first study demonstrated that AERD and OSA have been associated with each other; it seems to be affected by aspirin desesitization and number of nasal polypectomy operation. More prospective studies including more population are required to evidence it. Rather than only rhinitis or asthma, together with asthma and rhinitis have frequently OSA.

\section{Conflict of interest}

The authors whose names are listed immediately below certify that they have NO affiliations with or involvement in any organization or entity with any financial interest (such as honoraria; educational grants; participation in speakers' bureaus; membership, employment,

Table 3. Characteristic features of AERD patients with and without desensitizated.

\begin{tabular}{|l|l|l|}
\hline & $\begin{array}{l}\text { AERD with } \\
\text { desensitizated }\end{array}$ & $\begin{array}{l}\text { AERD without } \\
\text { desensitizated }\end{array}$ \\
\hline Patients; $\mathrm{n}(\%)$ & $9(60)$ & $6(40)$ \\
\hline Positive prick test:n $(\%)$ & $5(55)$ & $3(50)$ \\
\hline $\begin{array}{l}\text { Eosinofil } / \mathrm{mm}^{3} ; \text { mean }( \pm \mathrm{SD}) \\
\% ; \text { mean }( \pm \mathrm{SD})\end{array}$ & $\begin{array}{l}456.89(389.57) \\
6.23(5.20)\end{array}$ & $\begin{array}{l}473.92(333.84) \\
6.60(4.84)\end{array}$ \\
\hline Total IgE IU/ml; mean $( \pm \mathrm{SD})$ & $286.20(219.41)$ & $286.70(214.53)$ \\
\hline $\begin{array}{l}\text { Time interval }(\text { desensitization- } \\
\text { polysomnography) Day, median }(25-75 \\
\text { percentile })\end{array}$ & $30(12-180)$ & - \\
\hline $\begin{array}{l}\text { Number of nasal polip operation; mean }( \pm \mathrm{SD}) ; \\
\text { median }(25-75 \text { percentile) }\end{array}$ & $\begin{array}{l}4.44(6.12) \\
2(1-3)\end{array}$ & $\begin{array}{l}1.67(0.81) \\
2(1-2)\end{array}$ \\
\hline Abbreviations: AERD: Aspirin-exacerbated respiratory disease. & \\
\hline
\end{tabular}




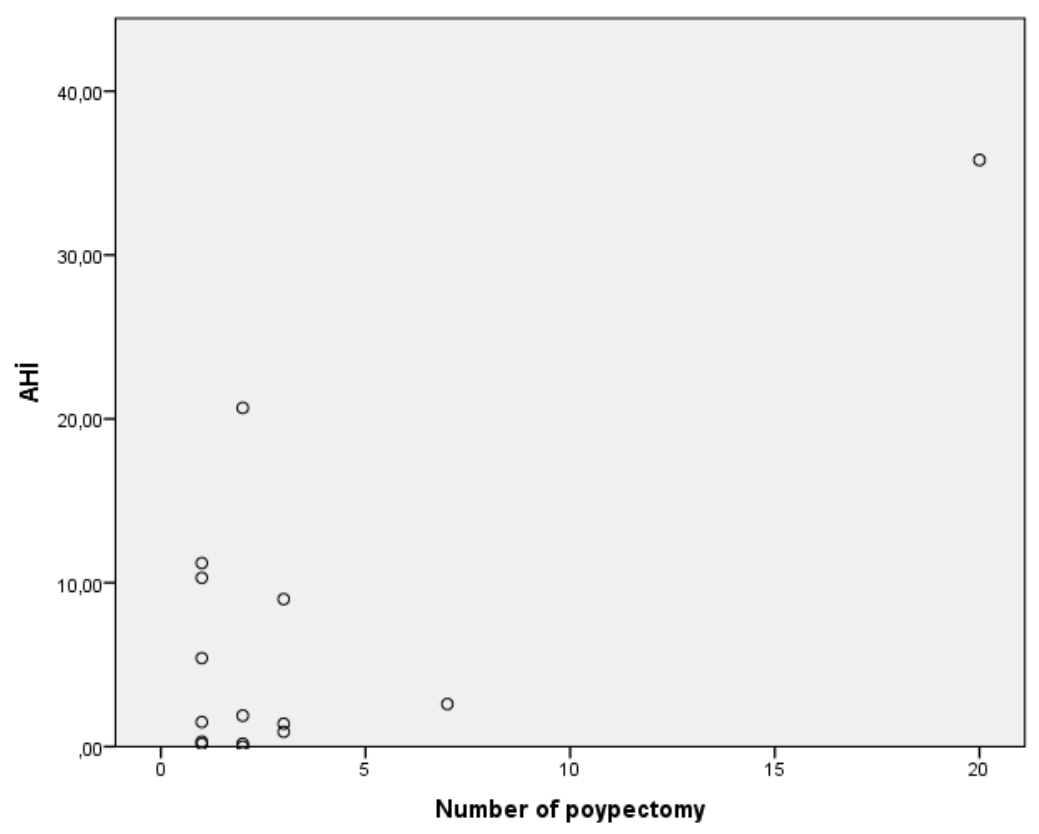

Figure 1. Corelation between $\mathrm{AHI}$ and number of polypectomy $\mathrm{p}=0.001, \mathrm{r}=0.74$.

consultancies, stock ownership, or other equity interest; and expert testimony or patent-licensing arrangements), or non-financial interest (such as personal or professional relationships, affiliations, knowledge or beliefs) in the subject matter or materials discussed in this manuscript.

\section{References}

1. Szczeklik A, Nizankowska E, Duplaga M (2000) Natural history of aspirin-induced asthma. AIANE Investigators. European Network on Aspirin-Induced Asthma. Eur Respir J 16: 432. [Crossref]

2. Christie PE, Tagari P, Ford-Hutchinson AW (1991) Urinary leukotriene E4 concentrations increase after aspirin challenge in aspirin-sensitive asthmatic subjects. Am Rev Respir Dis 143:1025. [Crossref]

3. Henderson WR Jr, Tang LO, Chu SJ, Tsao SM, Chiang GK, et al. (2002) A role for cysteinyl leukotrienes in airway remodeling in a mouse asthma model. Am J Respir Crit Care Med 165: 108-116. [Crossref]

4. Olopade CO, Christon JA, Zakkar M, Hua C, Swedler WI, et al. (1997) Exhaled pentane and nitric oxide levels in patients with obstructive sleep apnea. Chest 111: 1500-1504. [Crossref]

5. Canto Gde L, Pachêco-Pereira C, Aydinoz S, Major PW, Flores-Mir C, et al. (2015) Biomarkers associated with obstructive sleep apnea: A scoping review. Sleep Med Rev 23: $28-45$.

6. Dayyat E, Serpero LD, Kheirandish-Gozal L, Goldman JL, Snow A, et al. (2009) Leukotriene pathways and in vitro adenotonsillar cell proliferation in children with obstructive sleep apnea. Chest 135: 1142-1149.

7. Stanke-Labesque F, Back M, Lefebvre B, Tamisier R, Baguet JP, et al. (2009) Increased urinary leukotriene $\mathrm{E} 4$ excretion in obstructive sleep apnea: effects of obesity and hypoxia. $J$ Allergy Clin Immunol 124: 364-370.

8. ShenZ Y, Xu Z, Shen K (2011) Urinary leukotriene E4, obesity, and adenotonsillar hypertrophy in Chinese children with sleep disordered breathing. Sleep 34: 1135-1141.

9. Georgalas C (2011) The role of the nose in snoring and obstructive sleep apnoea: an update. Eur Arch Otorhinolaryngol 268: 1365-1373. [Crossref]

10. Fairbanks DN (1985) Effect of nasal surgery on snoring. South Med J 78: 268-270 [Crossref]

11. Craig TJ, Teets S, Lehman EB, Chinchilli VM, Zwillich C (1998) Nasal congestion secondary to allergic rhinitis as a cause of sleep disturbance and daytime fatigue and the response to topical nasal corticosteroids. Journal of Allergy and Clinical Immunology 101: 633-637.
12. Corren J, Togias A, Bousquet J (2003) Lung biology in health and disease. Volume 181: Upper and lower respiratory disease. New York: Marcel Dekke.

13. Bresciani M, Paradis L, Des Roches A, Vernhet H, Vachier I, et al. (2001) Rhinosinusitis in severe asthma. J Allergy Clin Immunol 107: 73-80. [Crossref]

14. D'Ambrosio CM, Mohsenin V (1998) Sleep in asthma. Clin Chest Med 19: 127-137. [Crossref]

15. The global strategy for asthma management and prevention, Global Initiative for Asthma (GINA) 2010 Available from: http://www.ginasthma.org/.

16. Comert S, Celebioglu E, Yucel T, Erdogan T, Karakaya G, et al. (2013) Aspirin 300 $\mathrm{mg} /$ day is effective for treating aspirin-exacerbated respiratory disease. Allergy 68: 1443-1451. [Crossref]

17. Silber MH, Ancoli-Israel S, Bonnet MH, Chokroverty S, Grigg-Damberger MM, et al (2007) The visual scoring of sleep in adults. J Clin Sleep Med 3: 121-131. [Crossref]

18. Berry RB, Budhiraja R, Gottlieb DJ, Gozal D, Iber C, et al. (2012) Rules for scoring respiratory events in sleep: update of the 2007 AASM Manual for the Scoring of Sleep and Associated Events. Deliberations of the Sleep Apnea Definitions Task Force of the American Academy of Sleep Medicine. J Clin Sleep Med 8(5): 597-619.

19. Kalpaklioglu AF, Kavut AB, Ekici M (2009) Allergic and nonallergic rhinitis: the threat for obstructive sleep apnea. Ann Allergy Asthma Immunol 103(1): 20-25.

20. Abdul Razak MR, Chirakalwasan N (2016) Obstructive sleep apnea and asthma. Asian Pac J Allergy Immunol 34: 265-271. [Crossref]

21. Lu H, Fu C, Li W (2017) Screening for obstructive sleep apnea syndrome in asthma patients: a prospective study based on Berlin and STOP-Bang questionnaires. $J$ Thorac Dis 9: 1945-1958. [Crossref]

22. Salerno FG, Carpagnano E, Guido P, Bonsignore MR, Roberti A, et al. (2004) Airway inflammation in patients affected by obstructive sleep apnea syndrome. Respir Med 98: 25-28. [Crossref]

23. Taillé C (2016) Obstructive Sleep Apnoea Modulates Airway Inflammation and Remodelling in Severe Asthma. PLoS One 11: e0150042. [Crossref]

24. Verse T, Pirsig W, Kroker B (1998) Obstructive sleep apnea and obstructing nasal polyps. Laryngorhinootologie 77: 150-152. [Crossref]

Copyright: (C2017 Tepetam FM. This is an open-access article distributed under the terms of the Creative Commons Attribution License, which permits unrestricted use, distribution, and reproduction in any medium, provided the original author and source are credited. 